\title{
Automated Micro-controller based room lighting energy management using dimmable CFL ballast considering day-light penetration
}

\author{
Mousam Ghosh ${ }^{1}$, Suman Ghosh ${ }^{2}$, Avik Chakraborty ${ }^{3}$, Dr. Saswati Mazumdar ${ }^{4}$ \\ ${ }^{I}$ Trainee Officer, West Bengal Financial Corporation. B-Tech, ME,Postal Address- Paharipara, PO+Dist- \\ Jalapiguri, West Bengal, Pin-735101, India \\ ${ }^{2}$ Assistant Professor, EE Dept., Bengal Institute of Engineering \& Management,Postal Address- Paharipara, \\ $P O+$ Dist- Jalapiguri, West Bengal, Pin-735101, India \\ ${ }^{3}$ Assistant Professor , ECE Dept., Bengal Institute of Engineering \& Management,Postal Address- Senpara, \\ PO+Dist- Jalapiguri, West Bengal, Pin-735101, India \\ ${ }^{4}$ Professor, Electrical Engineering Dept., Jadavpur University, Jadavpur, Kolkata-700032, West Bengal, India.
}

\begin{abstract}
Day lighting system offer tremendous potential for reducing the energy consumption of energy of electric lighting, but their usage has been inhibited by high cost and imperfect performance of current technologies. There are two types of basic techniques of day light linked electrical lighting system, one is automatic on/off and another is continues dimming. This paper contains a proposed technique of day light linked electrical lighting system using automated continues dimming techniques using a developed $36 \mathrm{~W} C F L$ dimming ballast maintaining visual comfort and required light level at low cost. It also helps to reduce the energy consumption when there is day light penetration in a room by dimming the artificial light level.
\end{abstract}

Keyword: day light linked electrical lighting system, automated continues dimming, visual comfort.

\section{Description}

In this paper a proposed system is designed for a single room with four CFL light. Generally CFL light is used for energy efficient indoor lighting. That is why CFL dimming technology is used.

DAY LIGHT

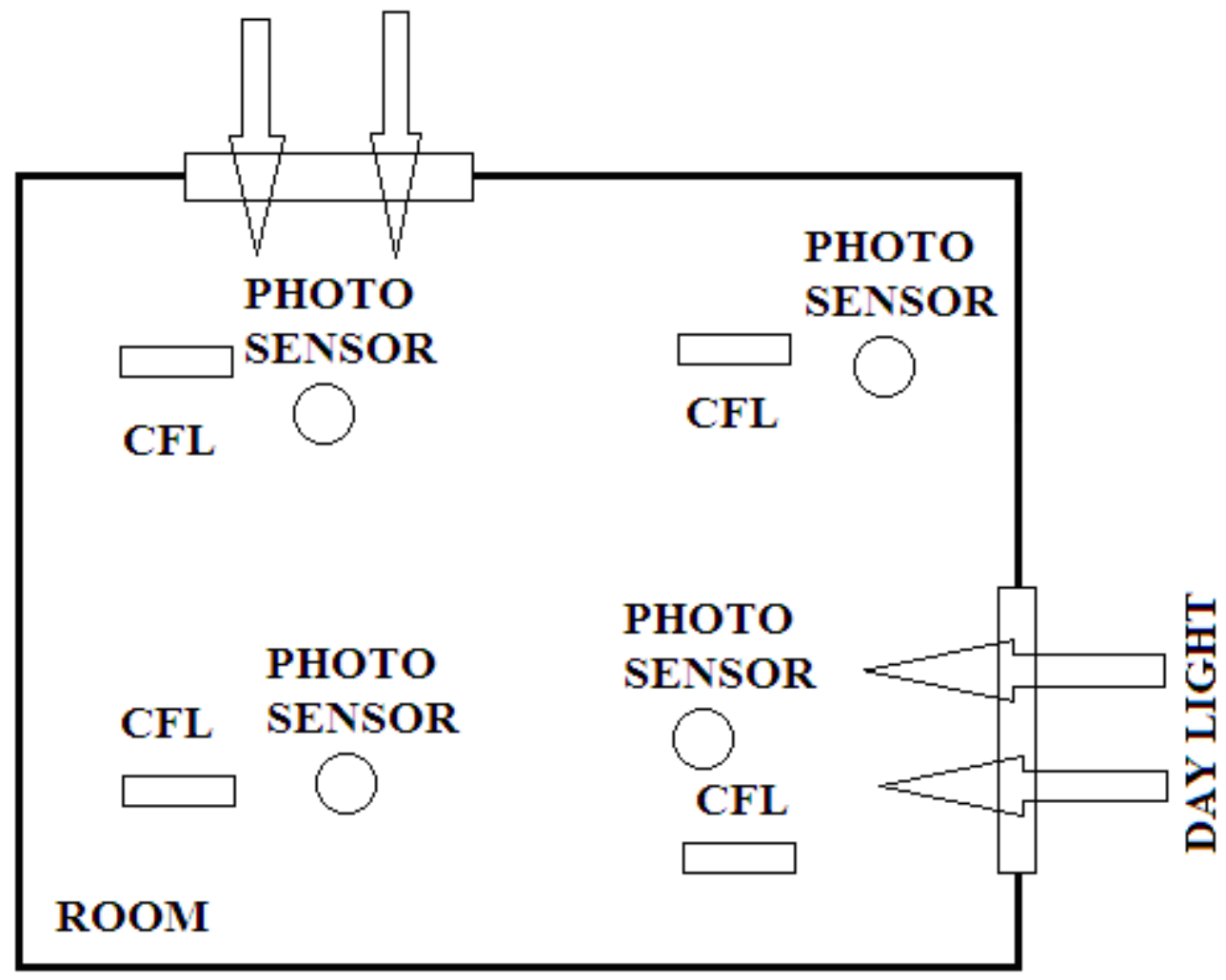

Fig.-1 Plan view of the room for which the proposed system is designed 


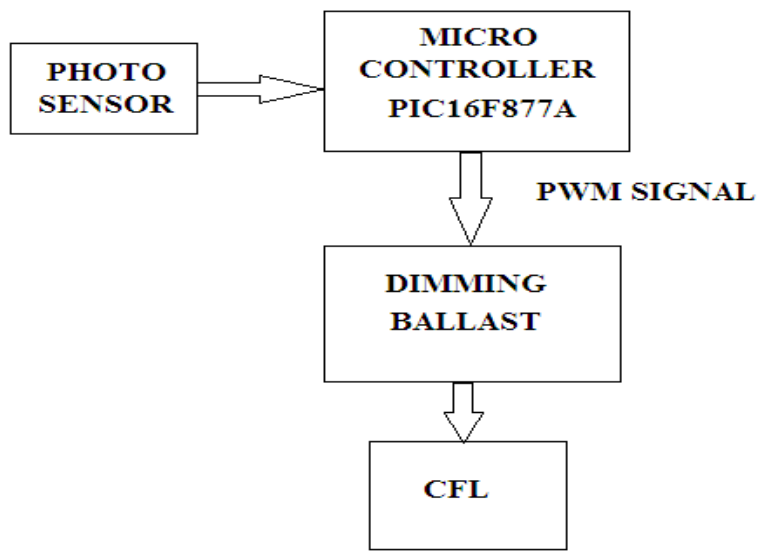

Fig.-2 Block Diagram of Electric Lighting Controller Block

A 36W CFL dimming ballast is developed in the laboratory [1]. The wattage consumption Vs percentage of the light output graph for the dimming ballast is given fig-3. This Ballast is basically PWM controlled ballast. By varying the PWM duty cycle the light output of the ballast can be varied. The graph of the PWM duty cycle Vs percentage of light output is shown in fig-4.

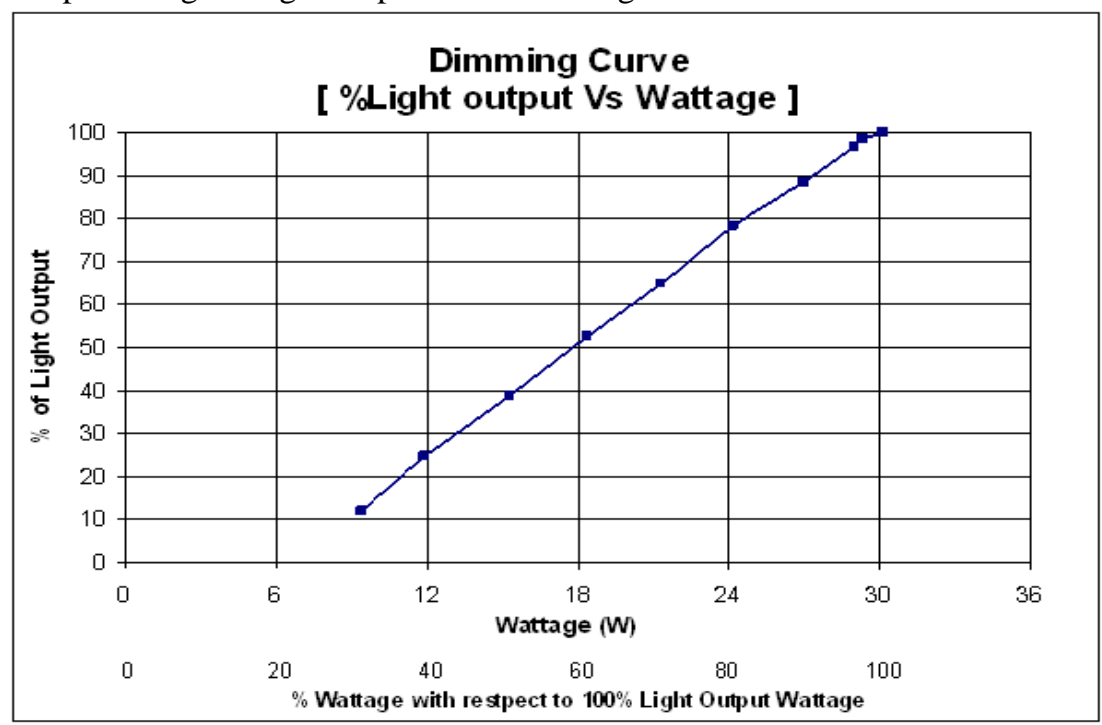

Fig.3 Dimming curve with respect to wattage (lamp plus ballast)

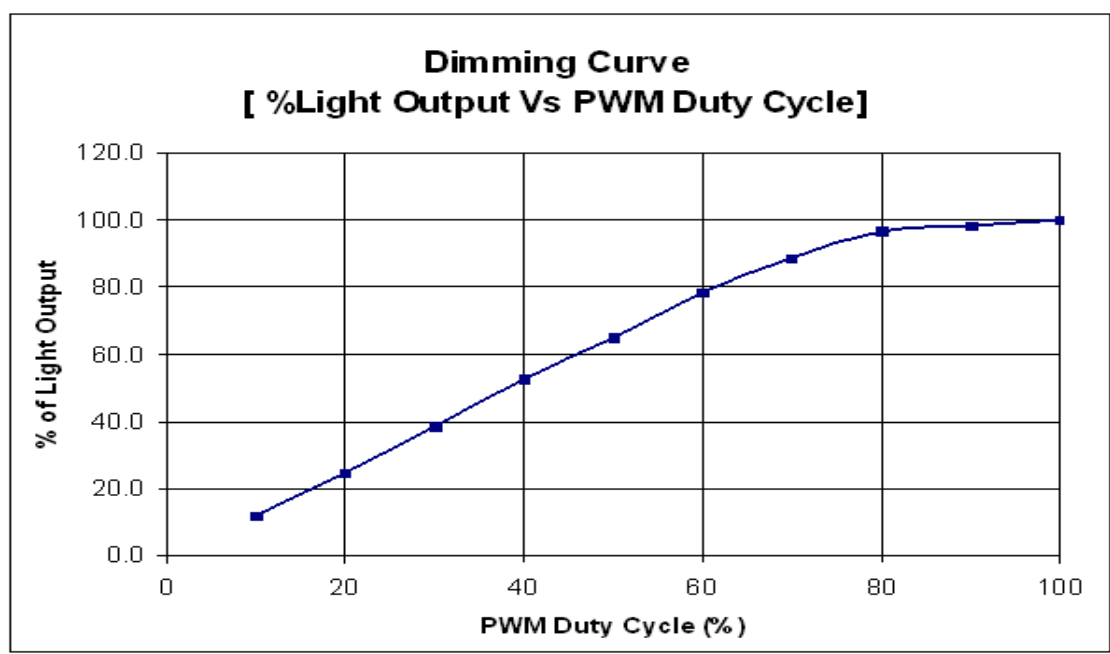

Fig.4 Dimming curve with respect to duty cycle 
From the fig-4 it is clear that if less amount of light is required then by reducing the controlled PWM signal duty cycle it can be achieved. From fig-3 it is understandable that if light output is reduced the wattage consumption also reduce linearly within a wide region. So due to day light penetration in a room if artificial light amount is required less then by controlling the dimming ballast the artificial light output as well as wattage consumption can be minimized maintaining the desired output level of the room.

From the fig-1 a design is proposed for a hall room. Where the lighting controllers are placed zone wise basis. Due to day light penetration different zones are illuminated differently by day light. So individual zone needs different electric light level to maintain the required overall light level. The basic control strategy (fig-5) is a particular zone is illuminated by the day light contribution but may be due to that contribution the required level of illumination is not achieved. So the remaining portion of light has to be given by the electric/artificial light. So depending upon the overall illumination level (day light contributed plus existing electric light contributed level) of a point of that zone controller will decide to increase or decrease the contribution level of the artificial/electric light by controlling the PWM signal duty cycle of the dimming ballast associated with the $\mathrm{CFL}$ of that zone. The controller gets the value of present light level from the photo sensor output placed in that zone. The sensor should be calibrated with lux level. Since the day light level through out the day is varying so to maintain the level automatically we have placed automated controller to control the electric light. [2-4]

So this is a close loop control strategy but in this case we can't use general control techniques like PD, PID etc. Since if light level varies due to day light penetration and the controller control the light level suddenly to achieve the desire level then it cause a visual discomfort for the persons who working in the room. Sudden fluctuation of light level cause a tremendous discomfort and the working people are disturbed and it hampers the ongoing task of those people. So to adjust the light level a slow but steady increasing/decreasing process is required. The control logic is shown in the flow chart.

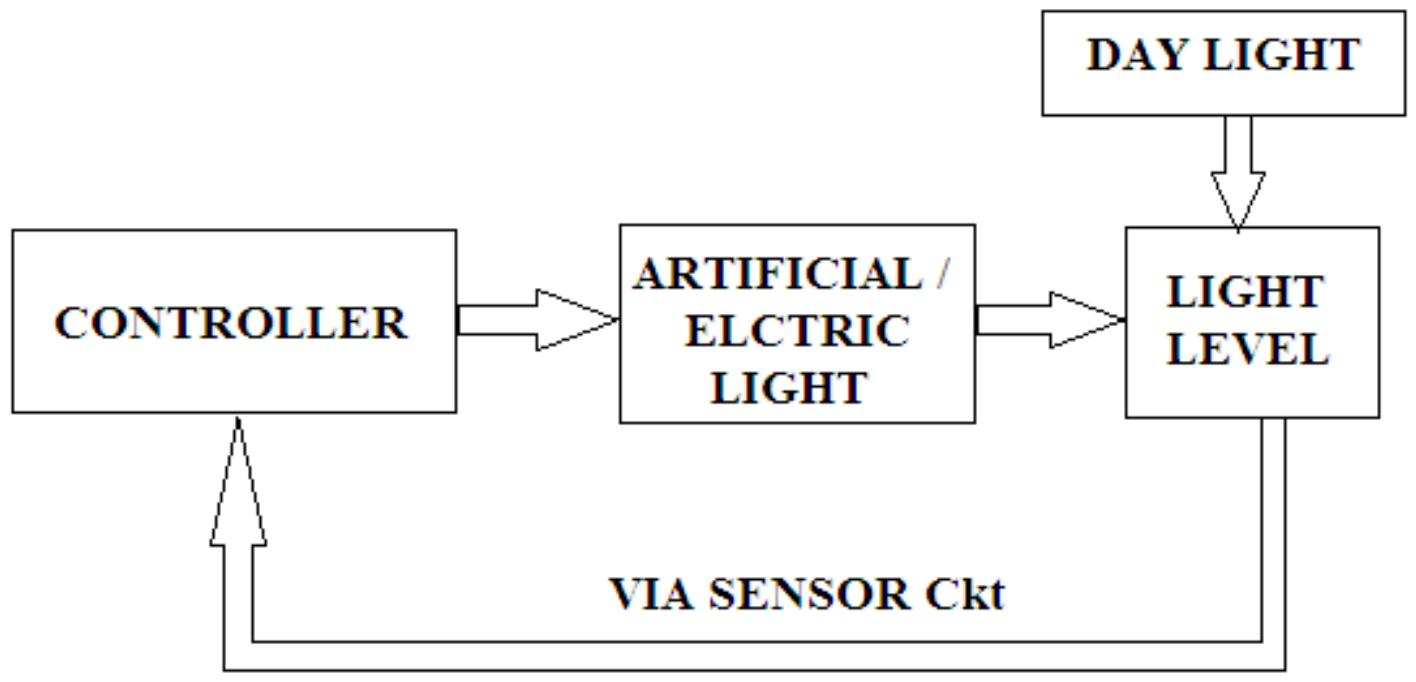

Fig.5 Basic Control Strategy

For example particular zone required avg 300 lux at a particular time span. Without electric light avg 200 lux can be achieved which is due to day light but if the electric light goes on with full glow then the zone avg light level say 600 lux. But if only 300 lux is required then the contribution of the electric light is around 100 lux further required instead of 400 lux $(600-200=400$ lux $)$. So reducing of the electric light output from 400 lux to 100 lux means running the lamp to its $25 \%$ output level, it is clearly observed from the fig- 3 that only $40 \%$ energy is consumed i.e. $60 \%$ energy can be saved. 


\section{FLOW CHART}

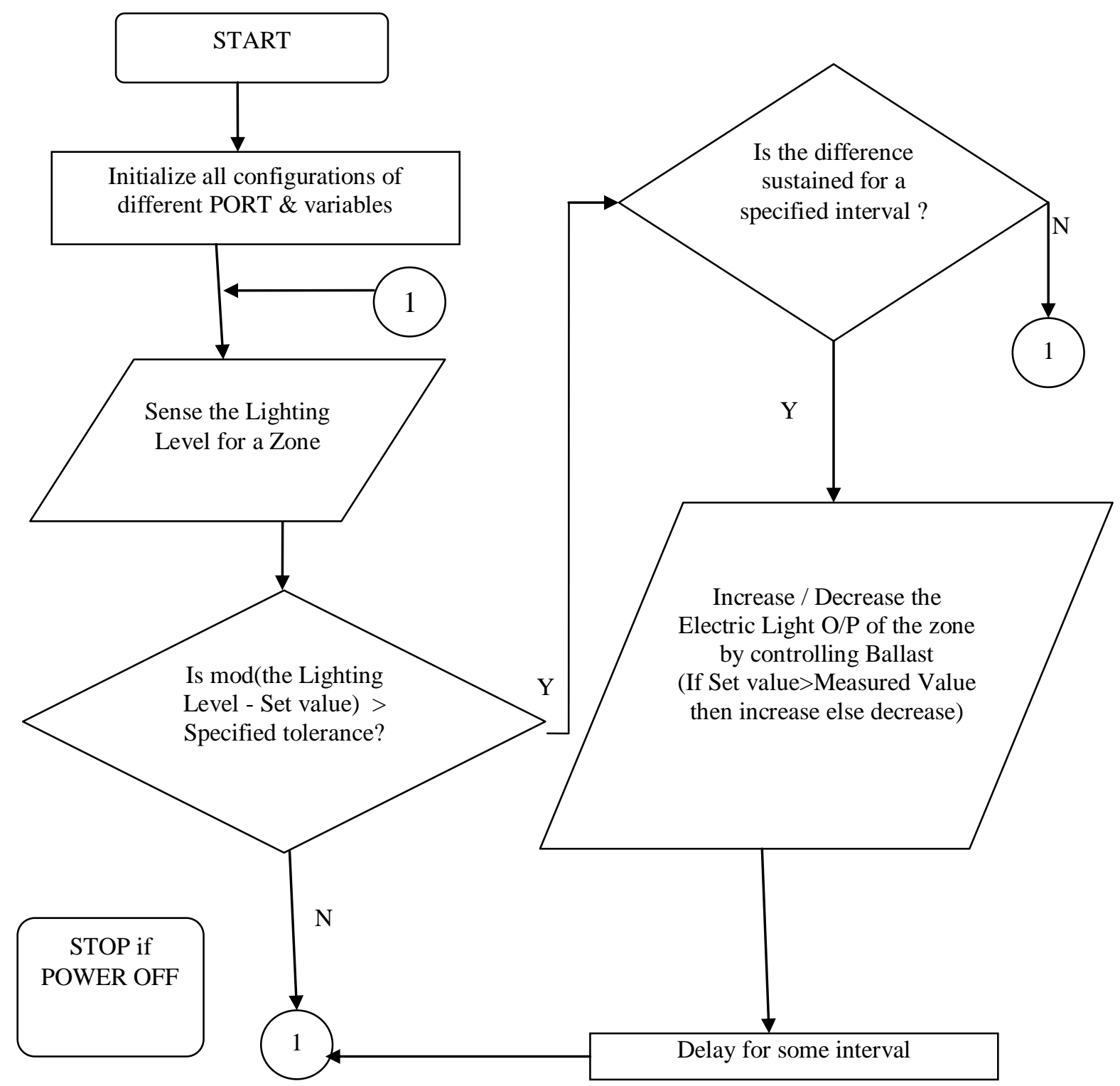

The flow chart of the zone wise controller logic is shown. Here a simplified basic logic is shown to control a zone lighting. Basically in every cycle the microcontroller sense and measures the present light level of a zone. Then it compares the measured light level with the specified required set value. If the said two values differ more than a tolerable value which is specified and that difference sustained for some interval then the controller starts working. Basically for a small change of light level if controller works then it hampers the visual comfort. Similarly if there is some movement of people in the room happens then for a small time the level of light for a particular zone may vary due to obstacle of the contribution of light from other zone. In this situation if controller wait for some interval to verify whether this situation will be stable or fluctuating to avoid visual discomfort. After satisfying this all conditions controller controls the light level by increasing or decreasing the electric light level in step by step process with proper time interval between two intervals to avoid visual discomfort.

\section{Conclusion}

In present situation energy conservation is the most valuable aspect to save the future from quick diminishing of renewable resources. Lighting is one of the field in which still we can have the provision to reduce the energy consumption by different techniques. One of the techniques is the adjustment of room electric light with daylight penetration as discussed in this paper. As per this design the energy consumption can be minimized automatically by the use of this controller with the developed dimming ballast, maintaining the 
required light level as well as without hampering the visual comfort. As per the fig-3 it is clear that if in a certain interval total output of the electrical light is not required then a considerable amount of energy can be saved with this technique. This is a technique in which a considerable electric energy can be saved by the introducing of natural resources of light energy. In this paper basically zone wise locally control of lighting is discussed but it can be further improved to zone wise centrally control of lighting.

\section{References}

[1] M. Ghosh, P. Das, S. Mazumdar, "Development of PWM Based 36W CFL Multi-stage Dimming Ballast", Proceedings of National Conference on Recent Development in Electrical Engineering, $10^{\text {th }}-11^{\text {th }}$ June, 2011, Jalpaiguri Govt. Engineering College, Jalpaiguri, West Bengal.

[2] S. Selkowitz, M.K. Hossain, M.M. Ali and M.R.I. Sheikh,(2011) "Integrating Automated Shading and Smart Glazings with Daylight”, International Symposium on Daylighting Buildings (IEA SHC TASK 31).

[3] A. D. Galasiu, M. R. Atif and R. A. MacDonald, "FIELD PERFORMANCE OF DAYLIGHT-LINKED LIGHTING CONTROLS", National Research Council Canada NRCC-44744.

[4] C. Aguilar-Castillo, C.D. García-Beltrán, C. Morcillo-Herrera, "Digitally Controlled Integrated Electronic Ballast with Dimming and Power Factor Correction Features", Journal of Applied Research and Technology, Vol.8 No.3 December 2010. 